\title{
Optimized tailings paste backfill combined with ore concentration processes
}

\author{
Xiaocong Yang Beijing General Research Institute of Mining and Metallurgy, China \\ Lijie Guo Beijing General Research Institute of Mining and Metallurgy / University of Science and \\ Technology Beijing, China
}

Caixing Shi Beijing General Research Institute of Mining and Metallurgy, China

Guangsheng Liu Beijing General Research Institute of Mining and Metallurgy, China

Xiaopeng Peng Beijing General Research Institute of Mining and Metallurgy / University of Science and Technology Beijing, China

Wenyuan Xu Beijing General Research Institute of Mining and Metallurgy, China

Zongnan Li Beijing General Research Institute of Mining and Metallurgy , China

Qi Jia Luleå University of Technology, Sweden

\section{Abstract}

Cemented paste backfill (CPB) is increasingly applied in underground mines and has a broad prospect considering its benefits in environmental protection and ground control. During paste production, a wellgraded aggregate is critical for the achievement of CPB. Mine tailings from the ore-dressing plant are commonly used as the fill aggregate. However, an ideal particle size distribution is difficult to obtain for the mine tailings which are roughly mixed with final residuum in ore concentration processes. In this study, a novel industrial method is proposed to select fill aggregates from different parts of ore-dressing processes. With combined design of concentration plant and backfill plant, the tailings with desired particle sizes and proportions during the mineral processing are chosen to produce CPB without disturbing the regular ore concentration. The problem of passively accepting final tailings from ore-dressing plant has been addressed.

\section{Introduction}

Paste backfill is being increasingly used in China as its advantages in maintaining stability of surrounding rock, decreasing surface subsidence and improving recovery rate of mineral resources (Liu and Cai, 1998). High strength can be reached by adding a small amount of cementing agent to ensure a desired roof contact and overall performance. In spite of its low filling cost, environmental friendliness, high safety and efficiency (Wu and Wang, 2015), paste filling is still far from being perfect. One of the problems that hinder the implementation of paste backfill is the selection and optimization of filling aggregate which is crucial to determining the applicability of filling scheme. Moreover, tailings gradation also has an influence on the filling quality, making the studies of filling aggregate gradation particularly significant.

At present, the filling system and mineral processing plant are designed and constructed separately in most mines. The tailings used in the filling system are mixed tailings produced at the final stage of mineral 
processing. Yet, it often differs from the ideal graduation of filling aggregate. As tailings are produced at multiple sub-processes, an optimized paste backfill technique using combinations of tailings is proposed in this paper. It mixes the tailings produced at different sub-processes of mineral processing in different proportions and produces filling aggregate with relatively ideal particle size, thus providing technical support for the preparation of paste backfill slurry.

\section{Ideal filling aggregate}

The ideal filling aggregate should firstly feature continuous gradation with fine grains filling in the pores among coarse particles, acting as 'lubricants' to reduce resistance loss of pipeline transportation. Furthermore, the fine-grained materials have a large surface area which can produce high water absorbing capacity to guarantee sufficient water-retaining property. They are evenly distributed among coarse particles when thoroughly mixed with water, making paste backfill slurry highly workable. Meanwhile, they also produce a stable structure to ensure a certain plasticity of paste backfill slurry at rest (Wang et al., 2014; Gan, 2009). Secondly, the ideal filling aggregate should also feature particular chemical compositions. Nonferrous metallic mines mainly consist of $\mathrm{SiO}_{2}$ and $\mathrm{CaO}$, accompanied with the metallic oxides which are the oxidized crude ore ungraded in mineral processing. Some of the mine tailings also contain mineral monomer residues (Wang et al., 2006). The chemical composition of tailings directly affects the performance of backfill. For example, when the content of $\mathrm{CuO}$ is greater than $3 \%$, the setting time of paste is significantly affected. For backfill which uses cement as cementing materials, the presence of pyrite minerals in filling materials would generate sulfate radical $\left(\mathrm{SO}_{4}{ }^{2-}\right)$ ions when in contact with air and water. The ions would erode cement and generate insoluble sulphoaluminate crystals and dihydrate gypsum. As a result, the volume of the fill body would expand more than two times, which increases its internal stress and causes damage to the backfill (Wang et al., 2005). In summary, the ideal filling aggregate should have both optimal gradation and optimum chemical composition to form dense structure.

The extensive use of filling aggregate in mines has gradually shifted from traditional mountain sand, sea sand, river sand, fine stone, and so on to industrial waste such as fly ash, tailings, slag, etc. Classified tailings have been the main source of filling aggregate for a considerably long time. With finer materials having been eliminated, the backfill slurry can be dehydrated quickly after entering the stope, hence significantly increasing the backfill strength. Nevertheless, the classification of tailings would inevitably lead to the insufficient sources of filling aggregate, and meanwhile, the inlet of abundant overflow tailings increases both the difficulty of tailings dam stack and the risk of dam failure.

At present, most of the nonferrous metallic mines in China cannot perform paste backfill due to a lack of or high cost of fly ash, slag and other aggregates. Limited by different sources of mining aggregate, the ideal aggregate can be difficult to obtain, considering the filling scheme, cost and other factors. Moreover, as the design and construction of filling system and mineral processing plant are considered separately in most mines in China, the tailings used by filling system are mixed ones produced at the final procedure of mineral processing. Those tailings are often uneven gradation, causing segregation, difficult dehydration and other problems.

Therefore, an optimized tailings paste backfill technology combined with mineral processing is proposed for mines where tailings are produced at multiple sub-processes of mineral processing plant. The key of this technology is to mix the tailings with different gradations in a certain proportion to form an optimized particle size, thus laying the foundation for preparation of paste backfill slurry. 


\section{$3 \quad$ Optimized tailings backfill combined with mineral processing}

Proportioning of filling materials is crucial for filling quality. By choosing proper materials and adjusting content of coarse and fine tailings, an optimum filling performance could be reached. Proportioning of backfill after optimization can not only guarantee its stability and flowability but also minimize filling cost. A certain amount of fine particles (generally, a minimum of $15 \%$ of fine particles smaller than $<20 \mu \mathrm{m}$ ) in the filling aggregate will prevent the backfill slurry from being segregated during transportation. These particles have a strong water retention capacity and enable the water to fill in the pores among micro-fine particles, thus guaranteeing the sufficient cement water to form fluidity of the backfill slurry. On the other hand, too high a content of fine particles $(<20 \mu \mathrm{m})$ would reduce the strength of backfill and increase the resistance to pipeline transportation.

To apply the optimized technology, particle size distribution of tailings from different sub-processes must be determined, with the theoretical calculation of optimized mixing ratio conducted and further confirmed by several lab tests, including water segregation test, permeation test, flowability test, etc. One of the following three methods can be selected to combine tailings from different mineral processes.

In the first method, the tailings produced from the gravity process is mixed with a certain proportion with the classified and overflowed tailings produced from the flotation process and is then concentrated in a sand silo or other dehydrating device. The concentrated tailings is blended with cementitious material and water to form paste filling slurry. The process is shown in Figure1.

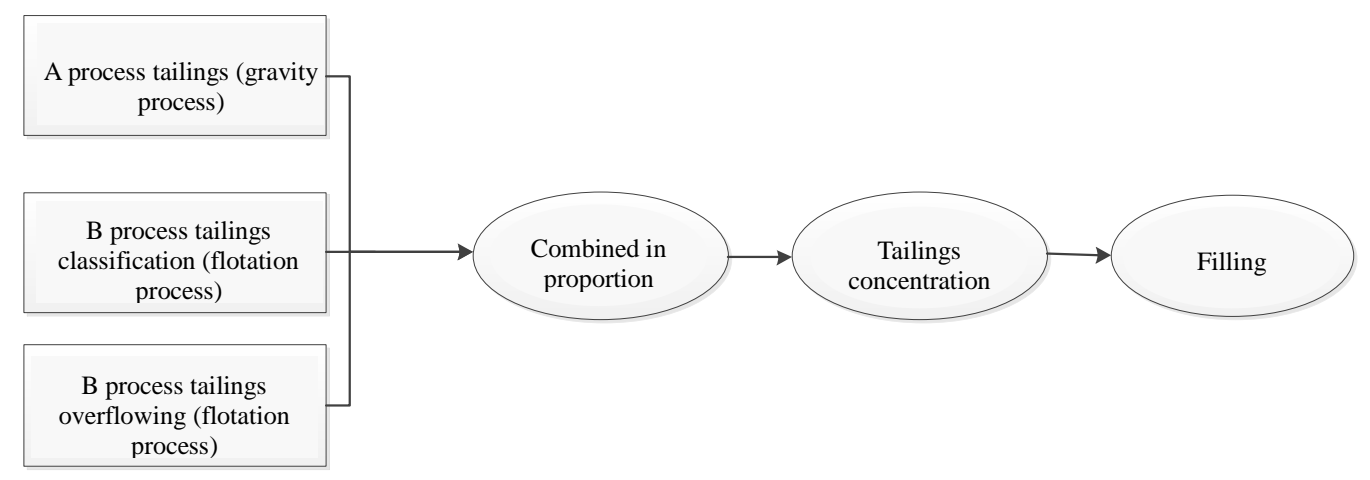

Figure 1 Processes of the first method

The second method (see Figure 2 ) is to firstly concentrate different tailings (i.e. tailings produced from the gravity process, classified tailings and overflowed tailings produced from the flotation process) and then have them mixed with a certain proportion to achieve a relatively ideal gradation. The mixed tailings are finally blended with the cementitious materials and water to prepare the paste filling slurry.

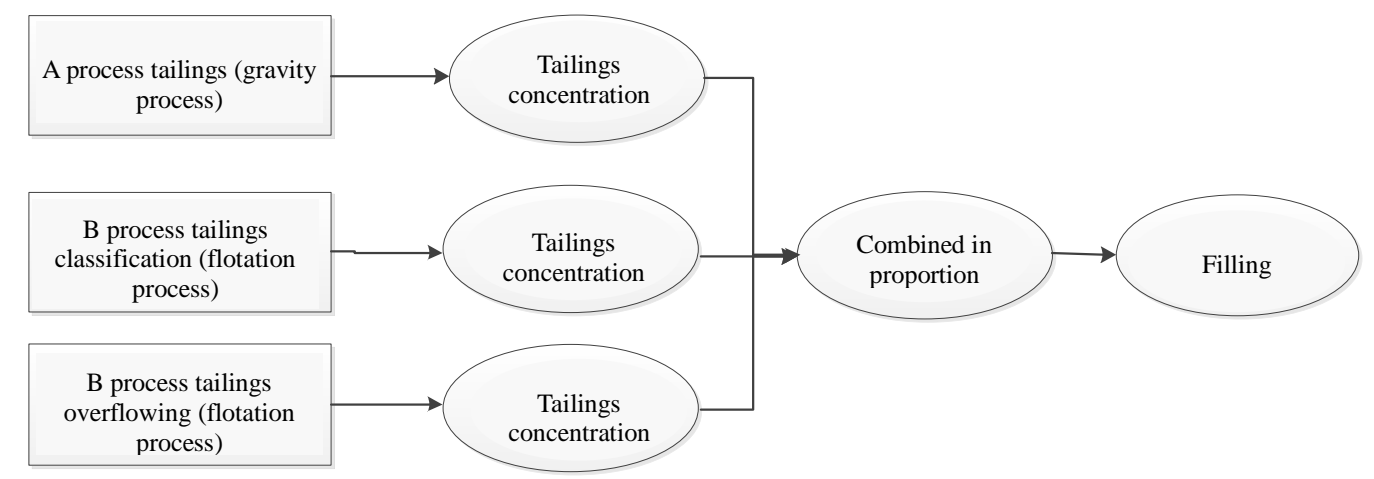

Figure 2 Processes of the second method

The first two methods have both advantages and disadvantages. The first one does not require many 
concentration facilities and equipment, and thus has relatively low cost. However, it might cause stratification at the concentration stage, thus unable to achieve the optimal gradation. The second demands highly on concentration facilities and equipment and is thus relatively costly. Nevertheless, it can ensure the even mixing of filling aggregates according to the designed proportion. The third method, however, is an incorporation of the first two by involving the blending of tailings produced from the first and second method respectively. The tailings are blended with a certain proportion and then mixed with cementitious agent and water to prepare the paste filling slurry.

\section{$4 \quad$ Application of the optimized model}

Anqing Copper Mine, Anhui, China, features open stope mining method followed by periodical classified tailings. The filling station contains three sets of independent filling systems, each containing a sand silo, a cement silo, a mixer and the supporting measurement equipment and automation management system. The tailings in the originally designed flotation workshop of the dressing plant are classified through four swirlers. The overflowing fine-grained tailings and underflow coarse-grained tailings are both delivered to the heavy media factory for secondary mineral processing. After that, the fine-grained tailings are discharged to the tailings pond, whereas the coarse-grained ones are pumped to the vertical sand silo in the filling station. The mineral processing flow is shown in Figure 3.

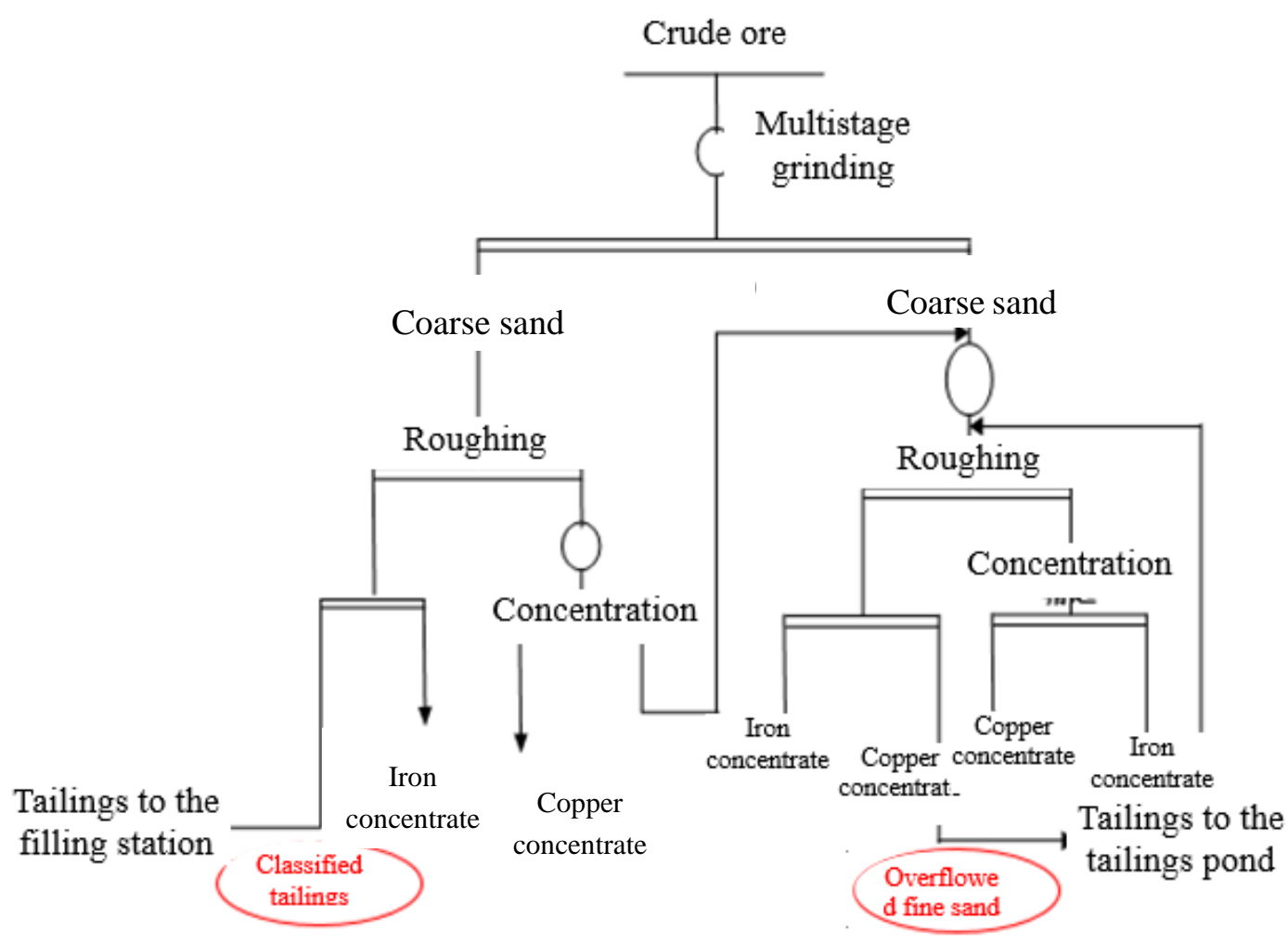

Figure 3 Mineral process flow in Anqing Copper Mine, Anhui, China

Several problems occur during filling processes with classified tailings, such as low filling concentration, filling slurry segregation, high filling cost and insufficiency of classified tailings filling in the future. Hence, taking into account the mineral processing, an optimized scheme is proposed to combine some of the overflowed fine sand with the classified tailings pumped to the tailings pond, to optimize the filling aggregate gradation, and to prepare the filling slurry with no segregation. Tests such as the sedimentation test, water segregation test, flowability test and proportioning test have been carried out on the basic parameters of tailings, which provides the basis for the technological transformation of filling system. 


\subsection{Tests on basic parameters of tailings}

\subsubsection{Particle size distribution}

A laser particle size analyzer was used to determine the particle size distribution (PSD) of the tailings. Figure 4 shows the PSD curves of both the classified and overflowed tailings as well as those of the mixture of classified tailings with $10 \sim 20 \%$ fines $(<20 \mu \mathrm{m})$ added and with the content between $15 \sim 20 \%$. The coefficient of uniformity and of the tailings curvature are listed in Table1.

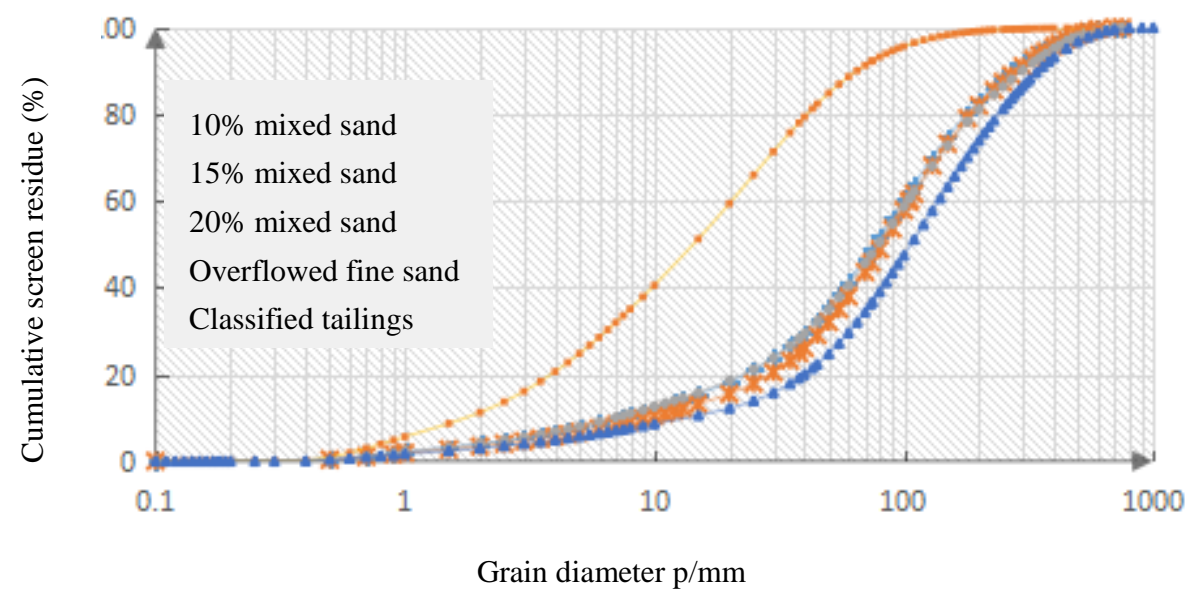

Figure 4 Particle size distribution

Table 1 Result of particle size analysis results for the tailings

\begin{tabular}{ccccccc}
\hline Type & $\begin{array}{c}-\mathbf{2 0} \boldsymbol{\mu m} \\
\text { content }\end{array}$ & $\mathbf{d}_{\mathbf{1 0}}$ & $\mathbf{d}_{\mathbf{3 0}}$ & $\mathbf{d}_{60}$ & $\begin{array}{c}\text { Coefficient of } \\
\text { uniformity } \mathbf{C u}\end{array}$ & $\begin{array}{c}\text { Coefficient of } \\
\text { curvature Cc }\end{array}$ \\
\hline $\begin{array}{c}\text { Overflowed fine } \\
\text { sand }\end{array}$ & $59.43 \%$ & 1.78 & 6.41 & 20.74 & 11.625 & 1.112 \\
10\% mixed sand & $15.54 \%$ & 9.31 & 46.57 & 105.45 & 11.329 & 2.209 \\
$15 \%$ mixed sand & $18.26 \%$ & 7.24 & 40.4 & 99.78 & 13.784 & 2.26 \\
20\% mixed sand & $18.56 \%$ & 6.93 & 40.99 & 103.72 & 14.967 & 2.338 \\
Classified tailings & $12.21 \%$ & 13.86 & 60.83 & 137.97 & 9.952 & 1.934 \\
\hline
\end{tabular}

The coefficient of uniformity and coefficient of curvature of different tailings were calculated. In terms of compactness, the gradation of classified tailings, overflowed tailings and mixed tailings is favorable. However, as the tailings will finally be prepared into slurry for pipeline transportation, the emphasis should be put on analyzing its gradation based on the experience in slurry pipeline transportation. According to the analysis, classified tailings smaller than $38 \mu \mathrm{m}$ accounted for $19.13 \%$ and those smaller than $74 \mu \mathrm{m}$ for $36.29 \%$. The particles $38^{\sim 74} \mu \mathrm{m}$ in size accounted for a smaller percentage, while the coarse particles with the size of +74 $\mu \mathrm{m}$ occupied $63.71 \%$, thus classifying the tailings as coarse tailings which could easily result in segregation in the filling slurry. By adding the fine tailings of different proportions, the PSD of mixed tailings was improved obviously. The percentage of classified tailings smaller than $20 \mu \mathrm{m}$ after adding the fines was between $15 \sim 20 \%$, which is the precondition for producing high concentration structural flow. However, the rheological test must be carried out to ensure that the tailings fulfill the requirement for flowability.

\subsubsection{Chemical composition}

A spectrum generator was used to test the chemical composition in tailings. The results are shown in Tables 2 and 3. 
Table 2 Results for quantitative analysis of classified tailings elements

\begin{tabular}{ccccccccccccccc}
\hline Element & $\mathrm{SiO}_{2}$ & $\mathrm{Al}_{2} \mathrm{O}_{3}$ & $\mathrm{TFe}$ & $\mathrm{FeO}$ & $\mathrm{MgO}$ & $\mathrm{CaO}$ & $\mathrm{Na}_{2} \mathrm{O}$ & $\mathrm{K}_{2} \mathrm{O}$ & $\mathrm{TiO}_{2}$ & $\mathrm{P}_{2} \mathrm{O}_{5}$ & $\mathrm{MnO}$ & $\mathrm{S}$ & $\begin{array}{c}\mathrm{Cu} \\
\text { Ignition }\end{array}$ \\
\hline $\begin{array}{c}\text { Content } \\
(\%)\end{array}$ & 46.52 & 6.2 & 7.86 & 5.44 & 8.99 & 19.2 & 1.64 & 0.25 & 0.27 & 0.18 & 0.21 & 0.61 & 0.11 & 5.08 \\
\hline
\end{tabular}

Table 3 Results for quantitative analysis of overflowed tailings elements

\begin{tabular}{ccccccccccccccc}
\hline Element & $\mathrm{SiO}_{2}$ & $\mathrm{Al}_{2} \mathrm{O}_{3}$ & $\mathrm{TFe}$ & $\mathrm{FeO}$ & $\mathrm{MgO}$ & $\mathrm{CaO}$ & $\mathrm{Na}_{2} \mathrm{O}$ & $\mathrm{K}_{2} \mathrm{O}$ & $\mathrm{TiO}_{2}$ & $\mathrm{P}_{2} \mathrm{O}_{5}$ & $\mathrm{MnO}$ & $\mathrm{S}$ & $\begin{array}{c}\mathrm{Cu} \\
\text { loss on } \\
\text { Ignition }\end{array}$ \\
\hline $\begin{array}{c}\text { Content } \\
\text { (\%) }\end{array}$ & 43.4 & 5.67 & 8.56 & 7.43 & 10.65 & 18.89 & 1.44 & 0.31 & 0.25 & 0.25 & 0.19 & 0.94 & 0.2 & 6.14 \\
\hline
\end{tabular}

The test results show a great amount of $\mathrm{CaO}$ and a certain amount of $\mathrm{MgO}$ and $\mathrm{FeO}$, which is conducive to cementing and filling. On the contrary, harmful elements like $S$ have a low content. Therefore, both classified tailings and overflowed tailings meet the filling requirements.

\subsection{Sedimentation test}

The sedimentation test was carried out in accordance with the concentrations of classified and overflowed tailings produced from the mineral processing. The results show rapid sedimentation of classified tailings and slow sedimentation of overflowed tailings. Meanwhile, the sedimentation test of mixed tailings was carried out, with the results shown in Table 4.

Table 4 Tailings sedimentation test data results

\begin{tabular}{cccc}
\hline Designation & Concentration & Stability time (min) & Average sedimentation velocity (cm/min) \\
\hline Classified tailings & $40 \%$ & 30 & 0.60 \\
$10 \%$ mixed sand & $40 \%$ & 40 & 0.40 \\
$15 \%$ mixed sand & $40 \%$ & 60 & 0.30 \\
$20 \%$ mixed sand & $40 \%$ & 80 & 0.22 \\
Overflowed tailings & $20 \%$ & 100 & 0.22 \\
\hline
\end{tabular}

The sedimentation velocity of classified tailings is approximately three times that of the overflowed tailings. The use of the first of the three optimized methods (i.e. mixing followed by concentrating) introduced above may lead to the stratification of classified tailings with the fast sedimentation of overflowed fine sand in the mixing process, thus causing the uneven particle size distribution of mixed tailings. In order to verify this conclusion, the following experiment was carried out: Firstly, the classified tailings and overflowed tailings were mixed in the simulation container at a certain flow ratio; after its surface stabilized, the sand was placed in the test mold, where the sampling was made at different heights. The results show a significant difference of tailings particle size composition among the upper, middle and lower parts (Figure 5). Therefore, the second method (i.e. concentrating followed by mixing) is preferred. 

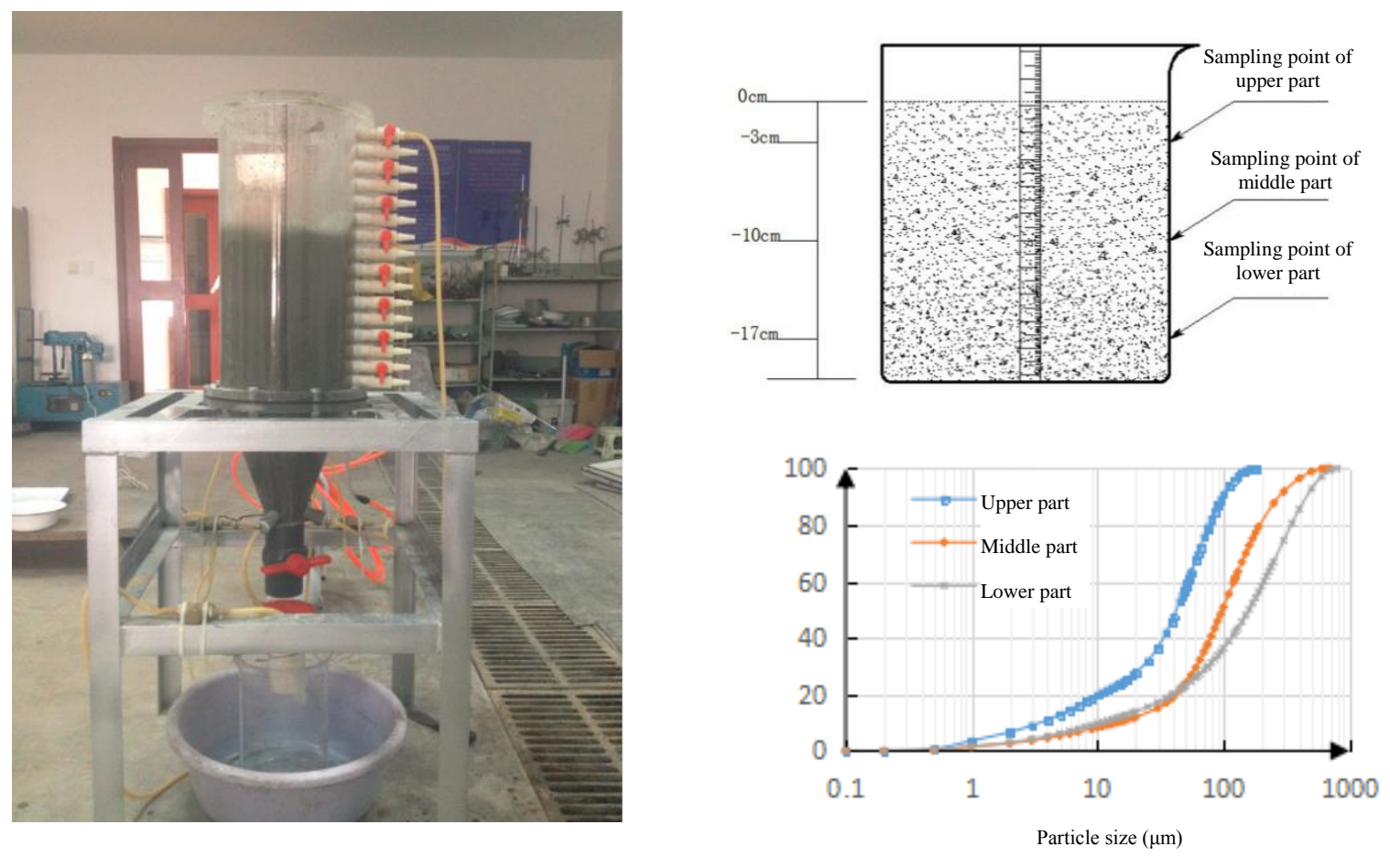

Figure 5 Verification test on the sedimentation stratification of the mixed tailings by the first method

\subsection{Water segregation test}

Bleeding rate is a key indicator for the optimal filling concentration with less bleeding in the filling stope, and it is also an important index to measure the dehydration amount of filling slurry after entering the stope. In paste filling, the bleeding rate of filling slurry needs to be maintained below $5 \%$. Therefore, water segregation test for different tailings filling slurry was carried out, with the test results are shown in Figure 6.
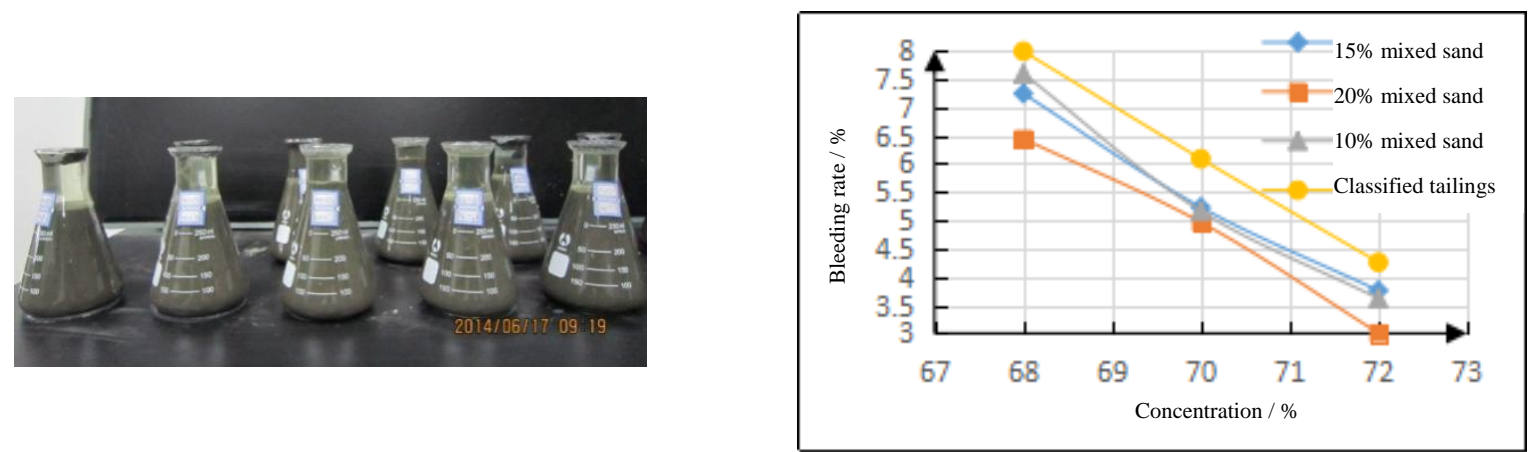

Figure 6 Results of water segregation test for different tailings

When the slurry concentration is $70 \%$ and the fine sand content is $15 \sim 20 \%$, the average bleeding rate is $4.8 \%$; when the slurry concentration is $72 \%$ and the fine sand content is $15 \sim 20 \%$, the average bleeding rate is $3.5 \%$. Based on previous experience, when the bleeding rate of filling slurry is below $5 \%$, the filling slurry meets the paste bleeding requirements. Therefore, this confirms that the concentration of filling slurry needs to be greater than $70 \%$, with the content of overflowed tailings within $15 \sim 20 \%$ to reach the optimal state.

\subsection{Slump test}

In order for the mixed tailings to possess a certain water retention capacity, the flowability of filling slurry needs to be ensured. Therefore, the test on the flow property of classified tailings and mixed tailings were carried out. A diffusance bucket was adopted for the flowability test, and a small slump cone was used to test on a piece of glass marked with scale. The slump cone has an upper and lower diameter of 3.5 and 6.0 
$\mathrm{cm}$, respectively, and a height of $6.0 \mathrm{~cm}$. In the test, the slump cone is firstly cleaned and then placed on a horizontal glass panel. The well mixed filling slurry are then poured into the slump cone from its upper mouth, with a steel ruler also used to scrape away extra slurry from the upper mouth. The slump is then quickly hoisted vertically and the filling slurry will form a circle on the glass panel. With the measurement of circle diameter in two vertical directions, the average value will be the slurry diffusance. The test process and results are shown in Figure 7.
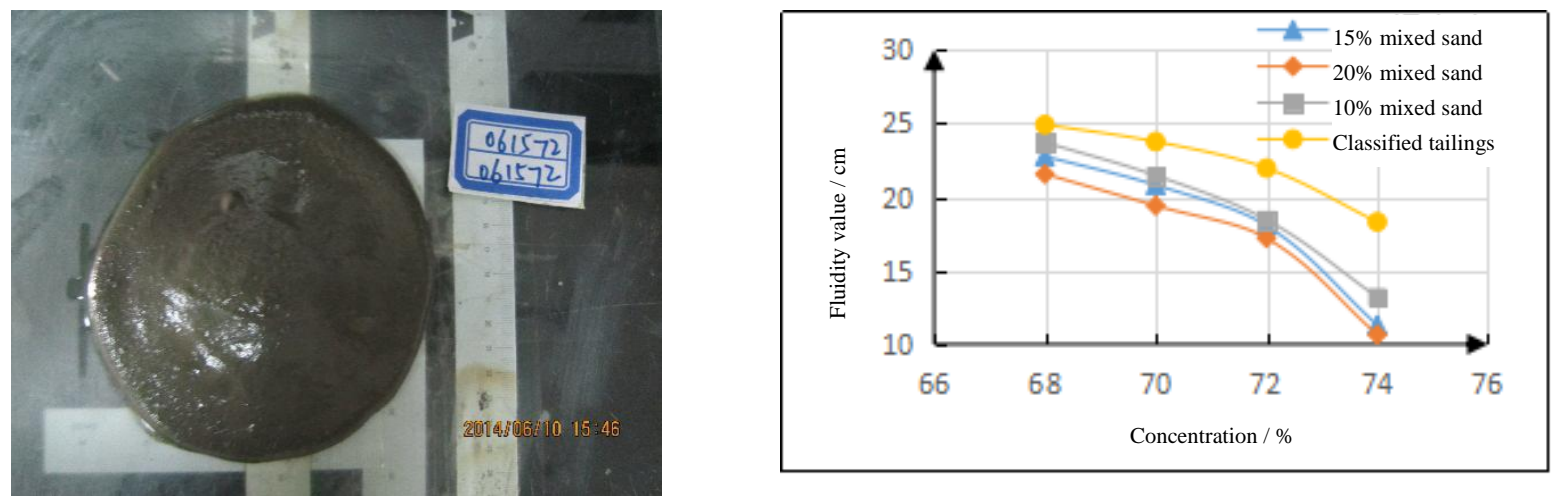

Figure 7 Slump test process and results

It can be seen that the diffusion diameter of filling slurry decreases with the increase of fines content on the whole. The increase of concentration leads to poorer flow property, showing that the addition of overflowed tailings together with high concentration are not favorable to slurry transportation.

\subsection{Optimization of filling technology based on mineral processing}

In the second optimizing method selected for this study, the coarse and fine tailings produced in the dressing plant will be pumped to the filling station by two pipelines. Among them, the classified coarse tailings will be pumped to the classified tailings silo for natural sedimentation and concentration, whereas the overflowed fine sand will be pumped to the fine sand silo for flocculating sedimentation and concentration. During filling, the concentrated coarse and fine tailings will be mixed according to the mass ratio of overflowed tailings/(overflowed tailings plus classified tailings) of $15 \%$. The aggregates will then be mixed with cement and water into paste filling slurry with the solids content of $70 \sim 72 \%$. The slurry will then be mixed thoroughly and filled in the underground stope by self-flowing in the filling borehole. The process is shown in Figure 8. 

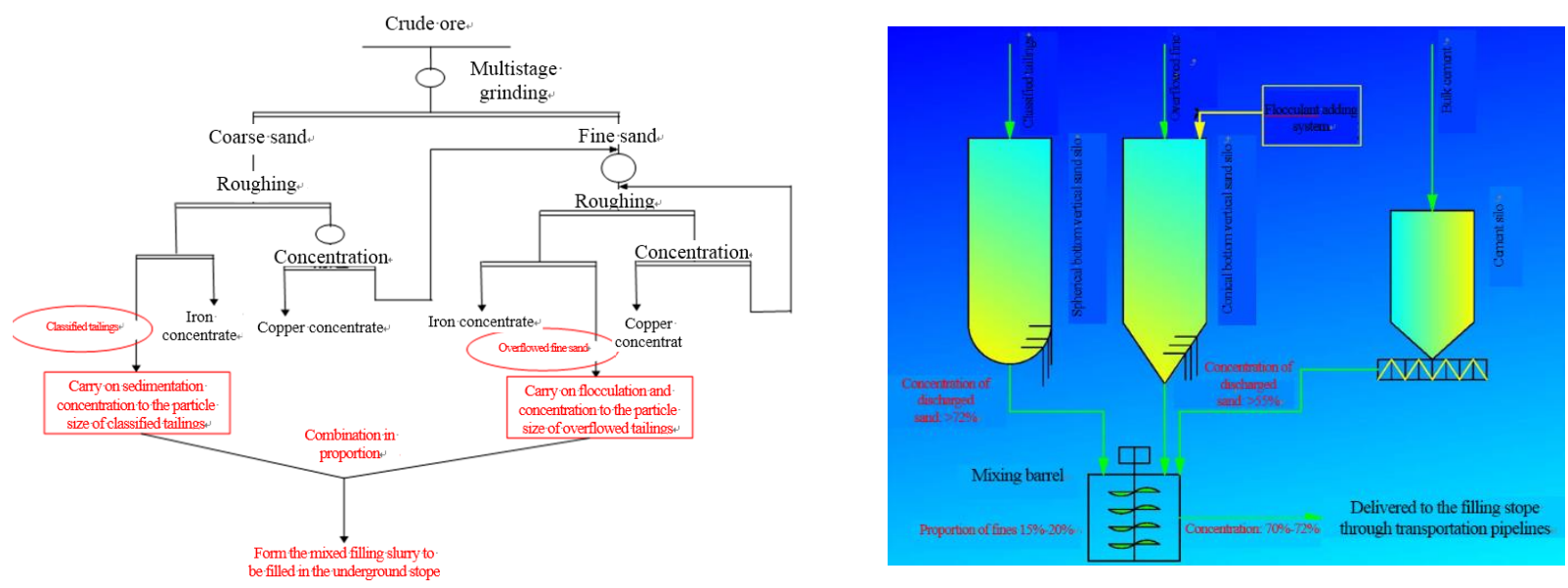

Figure 8 Filling technology at Anqing Copper Minea based on mineral processing

\subsection{Application of the optimized filling technology combined with mineral processing}

Having transformed the filling system according to the design scheme, the sampling test was carried out at the sampling mouth of the filling pipeline. The tests are fairly successful by having improved the filling quality, solved the problems of segregation and stratification of filling slurry for classified tailings, and realized the stable and efficient paste filling. Sampling of filling slurry with added tailings was carried out at the sampling port of the filling pipeline, with the sand discharging effect shown in Figure 9.

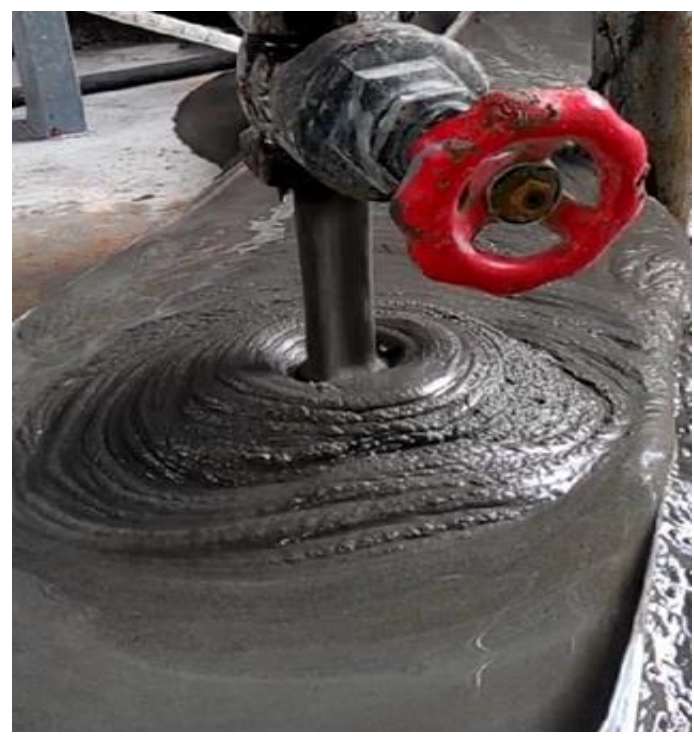

Figure 9 Sand discharging effect

In order to verify the advantages of the optimized method, especially the wholeness reflected in the uniformity of fillings, the sampling of underground fillings has been carried out. Two stopes were chosen, namely $2 \mathrm{P}$ stope and $10 \mathrm{R}$ stope. Among them, $2 \mathrm{P}$ is the stope after the transformation of filling system, and 10R stope is the stope prior to the transformation. The sampling position for both stopes was filling at the first layer. The cement-sand ratio is 1:4, and the sampling height and angle were consistent. The comparison of sampling results are shown in Figure 10. 


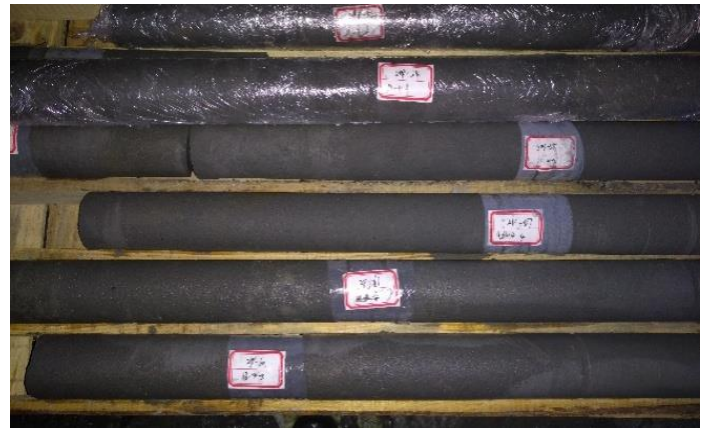

(a)

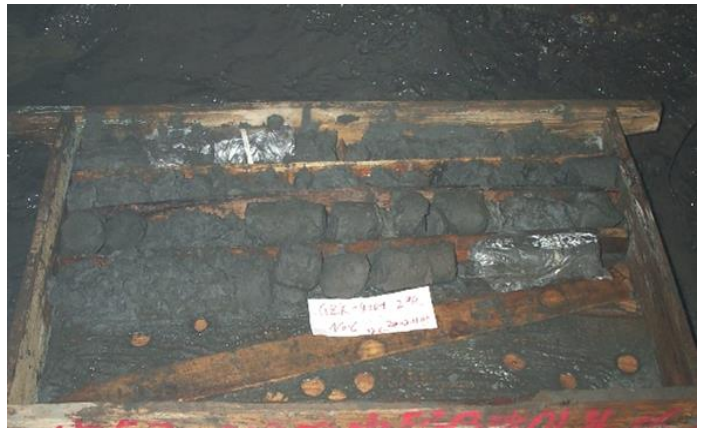

(b)

Figure 10 Comparison of sampling results of underground fillings; (a) 2P stope sampling results; (b) 10R stope sampling results

The sampling results showed that the fillings of $2 \mathrm{P}$ stope feature good integrity, but the sampling effect of 10R stope was poor, with parts of the fillings broken, hence showing the feasibility and reliability of the optimized method. Furthermore, this method also solves the problems of segregation and stratification of filling slurry and the uniformity of fillings strength. Meanwhile, adding some of the overflowed fine sand in the classified tailings not only solves the insufficiency of classified tailings, but can also reduce the stress and prolong the service life of tailings pond.

\section{$5 \quad$ Conclusions}

Based on tailings production of mineral processing for non-ferrous metal mines, the present study proposed an optimized method that combines filling technology with mineral processing. The core of this technology is to comprehensively consider factors such as the filling scheme and cost and to mix the tailings with different gradations and chemical compositions at a certain proportion. This technology also considers the conditions of tailings production from different stages of mineral processing so as to prepare the mixed tailings of continuous gradation. It combines the design and construction of filling system with that of the plant dressing process for an integrated design and provides insights for optimizing aggregates in the paste filling technology.

By carrying out the tests on the basic parameters of tailings (e.g. sedimentation test, water segregation test and fluidity test), this paper confirms the scheme of optimizing the filling technology based on mineral processing by practical applications. Through the sampling of filling slurry and the underground stope fillings, it can be proved that the filling technology scheme based on mineral processing is feasible and reliable, and it can solve the problems of segregation and stratification of filling slurry as well as the uniformity of fillings strength.

The optimized filling process based on mineral processing can not only solve the insufficiency of tailings due to single tailings, but can also consume more tailings and reduce the stress and prolong the service life of tailings pond.

\section{Acknowledgments}

The authors acknowledge the financial support from the National Science and Technology Support Program of China (No. 2013BAB02B02). National Key Research and Development Program of China (No.2016YFC0600709) is also gratefully acknowledged. The anonymous reviewers are gratefully acknowledged for their comments, which helped to improve the quality of the paper. 


\section{References}

Gan, F.W., 2009, 'Study on Tailings Composition and Pollution Transfer of Gejiu Stannum Polymetallic Mining Area', China University of Geosciences, Beijing.

Liu, T.Y., and Cai, S.J., 1998, 'Application and Research Situation of Paste Backfill Technology at Home and Abroad', China Mining Magazine.

Wang, F.Z., Zhu, Y.S. and Hui L., 2006, 'Discussion on Factors Affecting the Filling Quality of Dongguashan Copper Mine', Mining Technology.

Wang, H.J., Li, H. and Wu, A.X., 2014, 'New Definition of Paste Based on Full Tailings Gradation', Journal of Central South University of Technology: Natural Science Edition.

Wang, X.M., Xiao, W.G. and Zhang, Q.L., 2005, 'Theory and Technology of Filling for Deep Mines', Changsha: Central South University Press.

Wu, A.X. and Wang, H.J., 2015, 'Theory and Technology of Paste Filling for Metal Mines', Beijing: Science Press. 